\title{
ASPECTOS FITOGEOGRÁFICOS DA BACIA HIDROGRÁFICA DO ARROIO LAJEADO GRANDE, RS - BRASIL. 1 - O MEIO FÍSICO ${ }^{1}$
}

\author{
FABIANO DA SILVA ALVES ${ }^{2}$ LUIS EDUARDO DE SOUZA ROBAINA ${ }^{3}$ \\ JOSÉ NEWTON CARDOSO MARCHIORI ${ }^{4}$
}

\section{RESUMO}

O estudo do meio físico na bacia hidrográfica do arroio Lajeado Grande, oeste do Rio Grande do Sul, permitiu identificar, caracterizar e mapear a rede de drenagem e as unidades morfolitológicas, com base nas características do relevo, do substrato litológico e dos principais tipos de solos. Foram identificadas as seguintes unidades: colinas de arenito, colinas vulcânicas, cornijas de arenito, morrotes de arenito, morrotes vulcânicos e planície de acumulação. Todas as unidades foram mapeadas e representadas em mapa morfolitológico.

Palavras-chave: Fitogeografia, bacia hidrográfica, unidades morfolitológicas, arroio Lajeado Grande.

\section{ABSTRACT}

[Phytogeographic features in the basin of Lajeado Grande stream, Rio Grande do Sul - Brasil. 1 - The physical environment].

The physical environment study in the hydrogeographic basin of Lajeado Grande stream, western region of Rio Grande do Sul state, Brazil, allowed the recognition, characterization and mapping of the drainage net and morpho-lithological units, based on relief, lithological substratum and main soil types. Six units were identified: sandstone hills, volcanic hills, sandstone steps of middle rocky slopes, sandstone slope hills, volcanic slope hills and accumulation plains. All units were mapped and represented in a morpho-lithological map.

Keywords: Phytogeography, hydrogeographic basin, morpho-lithological units, Lajeado Grande stream.

\section{INTRODUÇÃO}

O oeste do Rio Grande do Sul carece de estudos detalhados sobre a composição, distribuição e vinculações da vegetação natural com o meio físico. Face a esta situação - e com o interesse de contribuir para o avanço do conhecimento científico, bem como alertar sobre a necessidade de conservação e preservação da

1 Extraído de "Estudos fitogeográficos na bacia hidrográfica do arroio Lajeado Grande - oeste do RS", Dissertação de Mestrado defendida pelo primeiro autor, em dezembro de 2008, no Programa de Pós-Graduação em Geografia - UFSM. Apoio: FAPERGS - Procorede III -0614357.

2 Prof., MSc., Universidade da Região da Campanha URCAMP.

3 Prof., Dr., Programa de Pós-Graduação em Geografia UFSM.

4 Prof., Dr., Programa de Pós-Graduação em Engenharia Florestal - UFSM. biodiversidade e das paisagens naturais no estado -, o presente trabalho expõe os primeiros resultados de estudos fitogeográficos desenvolvidos na bacia hidrográfica do arroio Lajeado Grande.

Na primeira fase, a análise integrada do meio físico buscou analisar, descrever e mapear a rede de drenagem, as formas de relevo, as estruturas litológicas e os principais tipos de solos, a fim de caracterizar as unidades homogêneas do terreno (unidades morfolitológicas) e gerar informações necessárias para a compreensão da dinâmica da vegetação natural na região.

Localizada no oeste do Rio Grande do Sul, entre os municípios de Alegrete e Manoel Viana, mais precisamente entre as coordenadas geográficas $55^{\circ} 20^{\prime} 28^{\prime \prime}$ e $55^{\circ} 36^{\prime} 42^{\prime \prime}$ de longitude oeste em relação ao meridiano de Greenwich, e $29^{\circ}$ 36' 20" e 29० 59' 52" de latitude sul, em relação a linha do Equador, a bacia do arroio Lajeado 


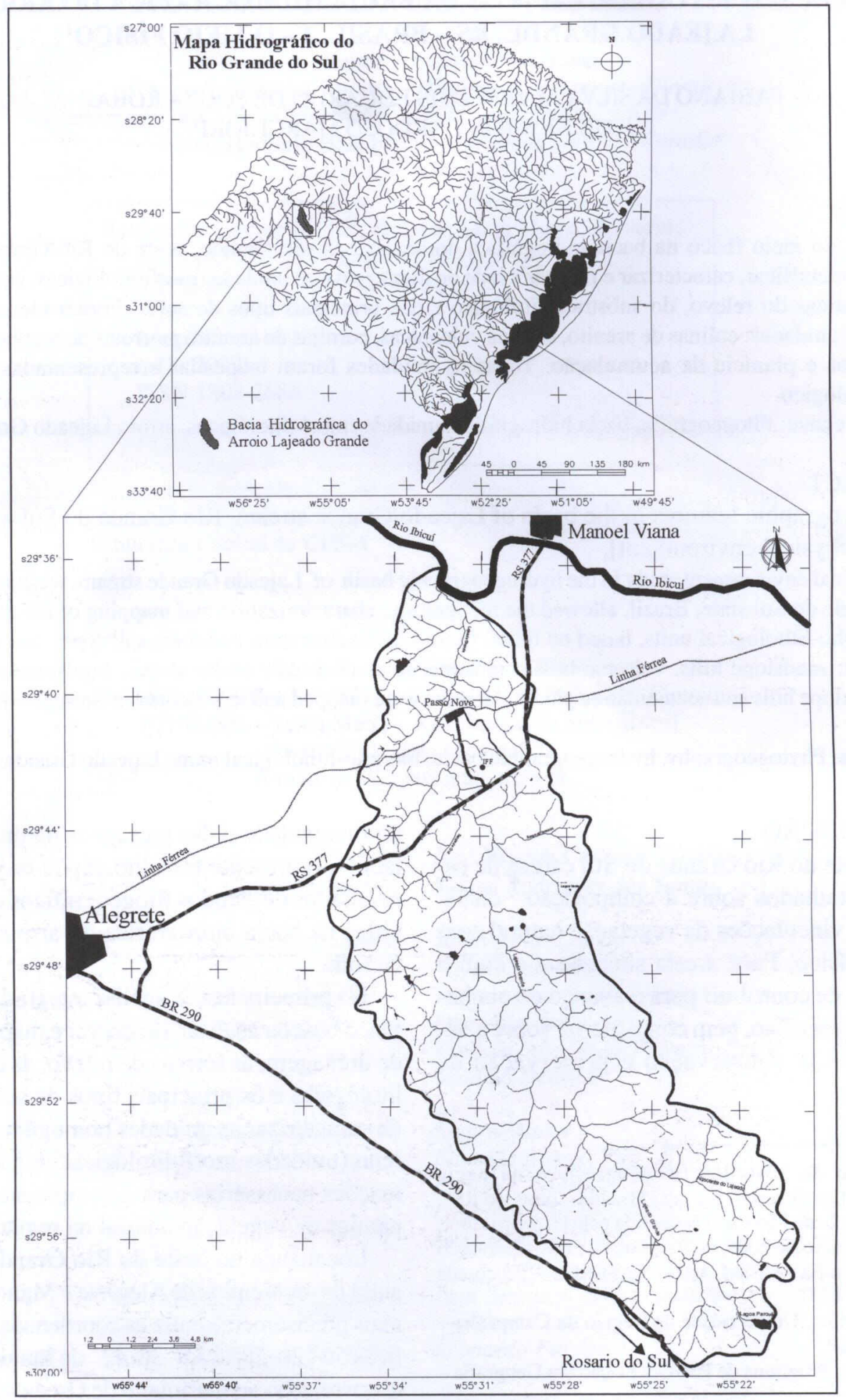

FIGURA 1 - Mapa de localização da bacia hidrográfica do arroio Lajeado Grande. 
Grande (Figura 1), apresenta importante diversidade de relevo e de substrato litológico.

\section{PROCEDIMENTOS METODOLÓGICOS}

$\mathrm{Na}$ análise do meio físico, foram analisadas, descritas e mapeadas: a rede de drenagem, as formas de relevo, as estruturas litológicas e os principais tipos de solos.

Os estudos foram desenvolvidos com base no conceito da unidade "bacia hidrográfica", a qual, segundo Botelho (1998), constitui uma célula natural que permite reconhecer e estudar as interrelações existentes entre os diversos elementos da paisagem e os processos que atuam em sua esculturação. Assim posto, a análise do meio físico baseou-se na caracterização da malha hidrográfica e na divisão da bacia em unidades morfolitológicas, definidas em função das características geológicas (litologias) e geomorfológicas, próprias do terreno.

Como bases metodológicas, foram utilizadas: a proposta de Trentin e Robaina (2005), para Mapeamento Geoambiental no Oeste do Rio Grande do Sul; os procedimentos de Paula e Robaina (2001), para mapeamentos geológi- co-geomorfológicos de bacias hidrográficas; as concepções de Lollo (1996), para a análise e diferenciação das formas do relevo; e as abordagens do IPT (1981), utilizadas na elaboração das cartas de atributos ou parâmetros.

Como base cartográfica, foram utilizadas as seguintes cartas topográficas da Diretoria do Serviço Geográfico - DSG, do Exército Brasileiro: Passo Novo (SH.21-X-C-VI-2), Manuel Viana (SH.21-X-D-IV-1), Rincão dos Costa Leite (SH.21-X-D-IV-3) e Arroio Caverá (SH.21-X-C-VI-4), todas em escala 1:50.000. Os dados obtidos foram georreferenciados e digitalizados, utilizando-se o software GPS TrackMaker Professional - GTM PRO, versão 4.6, e utilizadas imagens de satélite, ETM Landsat e Google Earth, como auxilio aos trabalhos. Para a definição e classificação das principais formas de relevo, valeu-se da proposição do IPT (1981).

Nos trabalhos de campo, as interpretações, feitas "a priori", foram confirmadas e/ou corrigidas mediante a realização de perfis. A caracterização da litologia e dos solos presentes nas unidades de relevo previamente definidas,

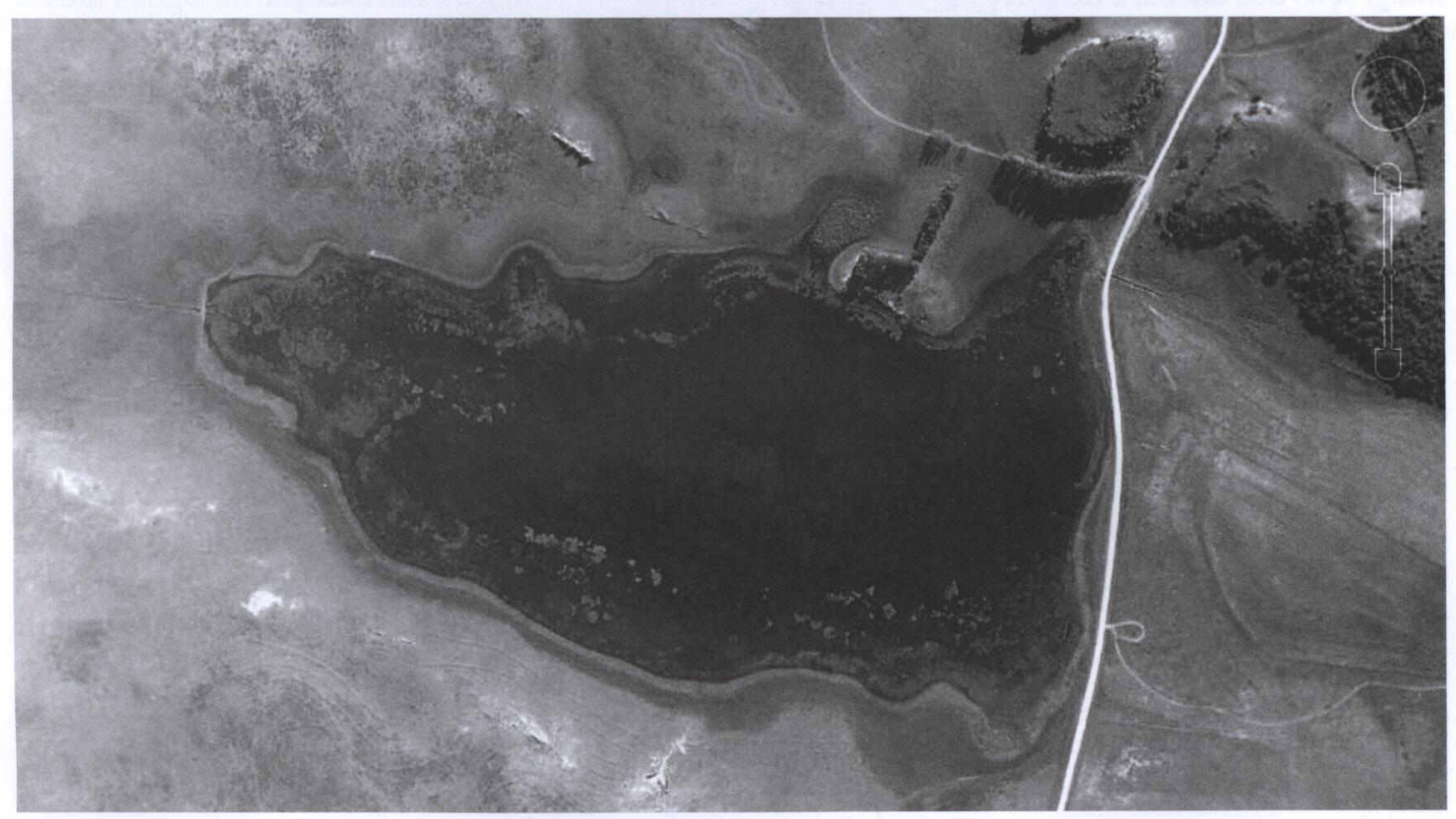

FIGURA 2 - A lagoa Parové, com cerro homônimo na parte superior da imagem. (Google Earth, 2008). 


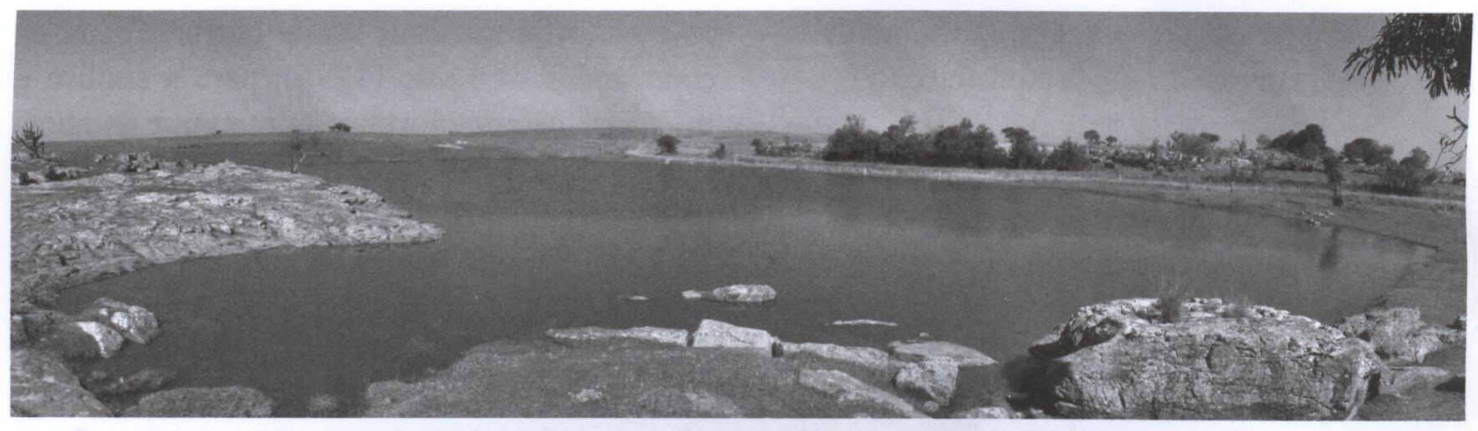

FIGURA 3 - Vista geral da lagoa Verde, com afloramentos areníticos da Formação Guará (2008).

foram desenvolvidas a partir de observações e descrições feitas a campo. Mediante perfis realizados ao longo da área, os estudos litológicos basearam-se na análise "in loco" de afloramentos rochosos, com coleta de amostras petrográficas e descrição dos principais tipos de solos derivados.

Em laboratório, todas as informações foram compiladas, obtendo-se, como resultado, a definição e caracterização das unidades geológico-geomorfológicas existentes. Na sequência, com o uso do software GTM PRO, para a integração dos dados, e do software Corel Draw X3, para a edição gráfica, elaborou-se o Mapa Morfolitológico, com a localização das distintas unidades de relevo e seus respectivos substratos.

\section{CARACTERIZAÇÃO DO MEIO FÍSICO}

Afluente da margem esquerda do rio Ibicuí, o arroio Lajeado Grande tem 61,044 km de comprimento e drena uma bacia hidrográfica de $493,186 \mathrm{~km}^{2}$. De forma alongada e padrão retangular-dendrítico, a bacia tem orientação sudeste-noroeste no alto e médio curso, sofrendo uma inflexão, no baixo curso, que a redireciona no sentido sul-norte, até sua foz no Ibicuí. Bacia de $5^{\mathrm{a}}$ ordem, de acordo com as proposições de Strahler (1974), apresenta altitudes entre 77 m (na foz) e $260 \mathrm{~m}$ (alto curso). A rede de cap- tação, não muito extensa, tem como principais afluentes a sanga da Cruz e a sanga do Graxaim.

Uma das principais nascentes do Lajeado Grande - a lagoa Parové (Figura 2), lago natural com área superior a 45 hectares -, quando transborda também constitui-se em nascente do arroio Itapevi. Além desta, existem na bacia outros lagos naturais, porém de menor tamanho: é o caso da lagoa dos Curupis, da lagoa Vermelha e da lagoa Verde (Figura 3). Vinculados, frequentemente, a afloramentos de rocha arenítica, tais lagos formam-se principalmente nos topos planos de colinas. Com exceção da lagoa Parové, nenhuma outra alcança dois hectares de área alagada, pouco ultrapassando a profundidade de um metro.

As unidades morfolitológicas reconhecidas na bacia em estudo são representadas na Figura 4 (Mapa Morfolitológico) e caracterizadas a seguir:

\section{Colinas}

Unidade morfolitológica mais abundante na bacia hidrográfica, as colinas, conhecidas regionalmente por coxilhas, ocupam cerca de $80 \%$ da área total. Elevações mamelonares do terreno, com altitudes relativamente baixas e declives suaves, as colinas conferem à paisagem um aspecto suavemente ondulado. $\mathrm{Na}$ área em estudo, esta forma de relevo permite o reconhecimento de duas subunidades, de acordo com as 


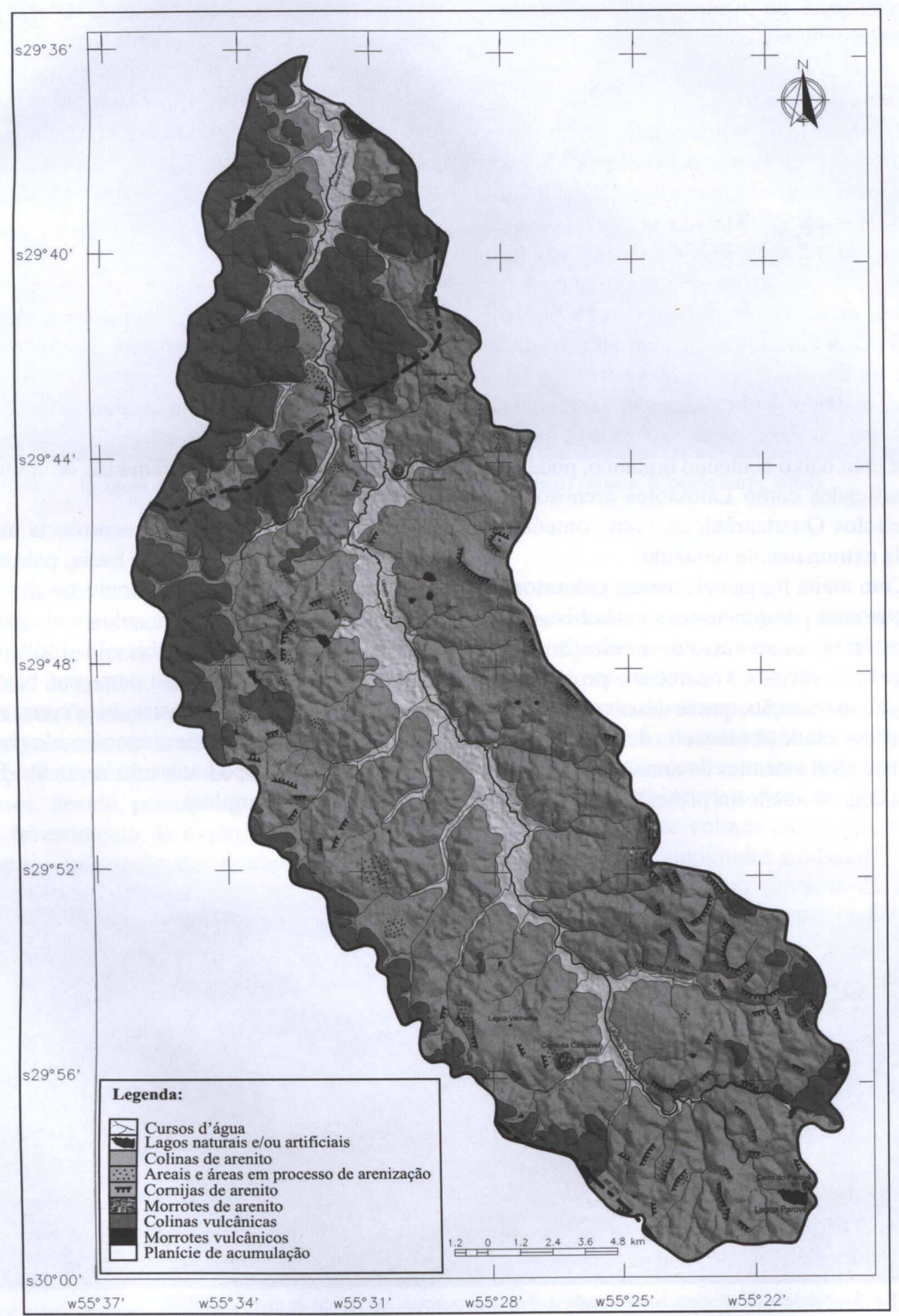

FIGURA 4 - Mapa morfolitológico da bacia hidrográfica do arroio Lajeado Grande. 
características do substrato rochoso: colinas de rochas areníticas e colinas de rochas vulcânicas.

\section{Colinas de arenito}

Unidade mais representativa na bacia, as colinas de arenito possuem substrato rochoso composto predominantemente de arenitos fluviais da Formação Guará e arenitos eólicos da Formação Botucatu. Encontradas, sobretudo, no médio e alto curso da bacia, apresentam amplitudes médias em torno de 10 metros, declividades entre 4 e $8 \%$ e altitudes variadas, com mínimas a cerca de 80 metros, no baixo curso, e máximas ultrapassando 200 metros, no alto curso. Os solos, sempre arenosos, quartzosos e com baixo conteúdo orgânico, podem ser classificados como Latossolos arenosos e/ou Neossolos Quartzarênicos, com conteúdo de argila extremamente reduzido.

Com muita frequência, nestas colinas registram-se areais de dimensões significativas e inúmeras áreas em processo de arenização. Estas, apresentam ravinas, voçorocas e pequenos núcleos de arenização, que se desenvolvem geralmente associados à cabeceira de drenagem, junto à base dos morrotes de arenito e/ou vinculados a degraus rochosos presentes à meia encos- ta (Figura 5). A arenização resulta, certamente, da intensificação do escoamento superficial na área de contato entre o arenito silicificado exposto e o arenito friável, presente no interior das colinas. Os areais de maior extensão associam-se principalmente à base dos morrotes de arenito e junto ao vale da drenagem principal.

\section{Colinas vulcânicas}

Esta unidade estrutura-se em substrato de rochas vulcânicas básicas, originadas de derrames provenientes do vulcanismo fissural ocorrido na bacia do Paraná na Era Mesozóica. Tais rochas compõem uma camada delgada (até 20 metros de espessura) sobreposta ao arenito Botucatu, por vezes com camadas de arenito intertrápico.

As colinas vulcânicas têm ocorrência mais significativa no baixo curso da bacia, próximo à foz com o rio Ibicuí, bem como no divisor oeste. Em geral, apresentam solos mal desenvolvidos (Neossolos e Cambissolos-litólicos), com afloramento de lajes ou pequenos blocos rochosos. Nos topos e encostas, bem como nas porções de topo-base, podem ocorrer solos bem desenvolvidos, do tipo Latossolo Vermelho-Escuro, com textura argilosa.

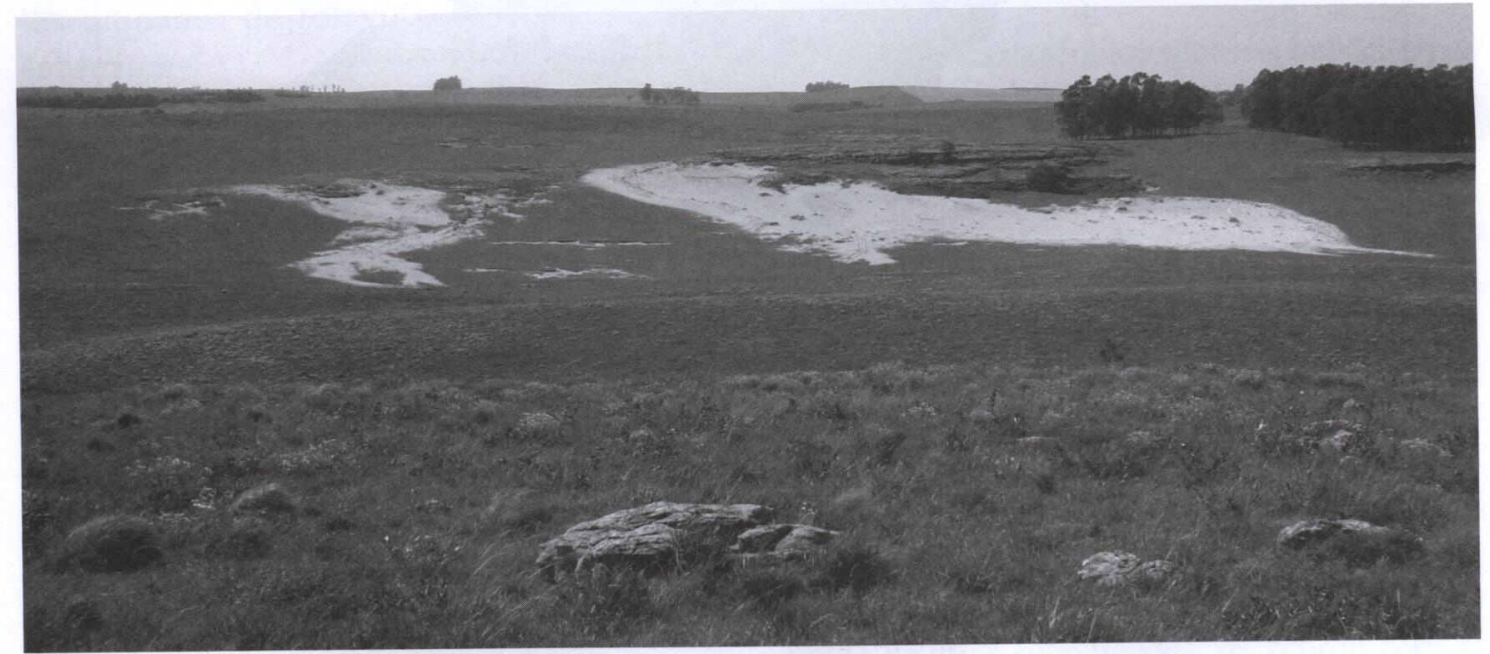

FIGURA 5 - Núcleos de arenização associados a degraus rochosos em colina de arenito (2008). 


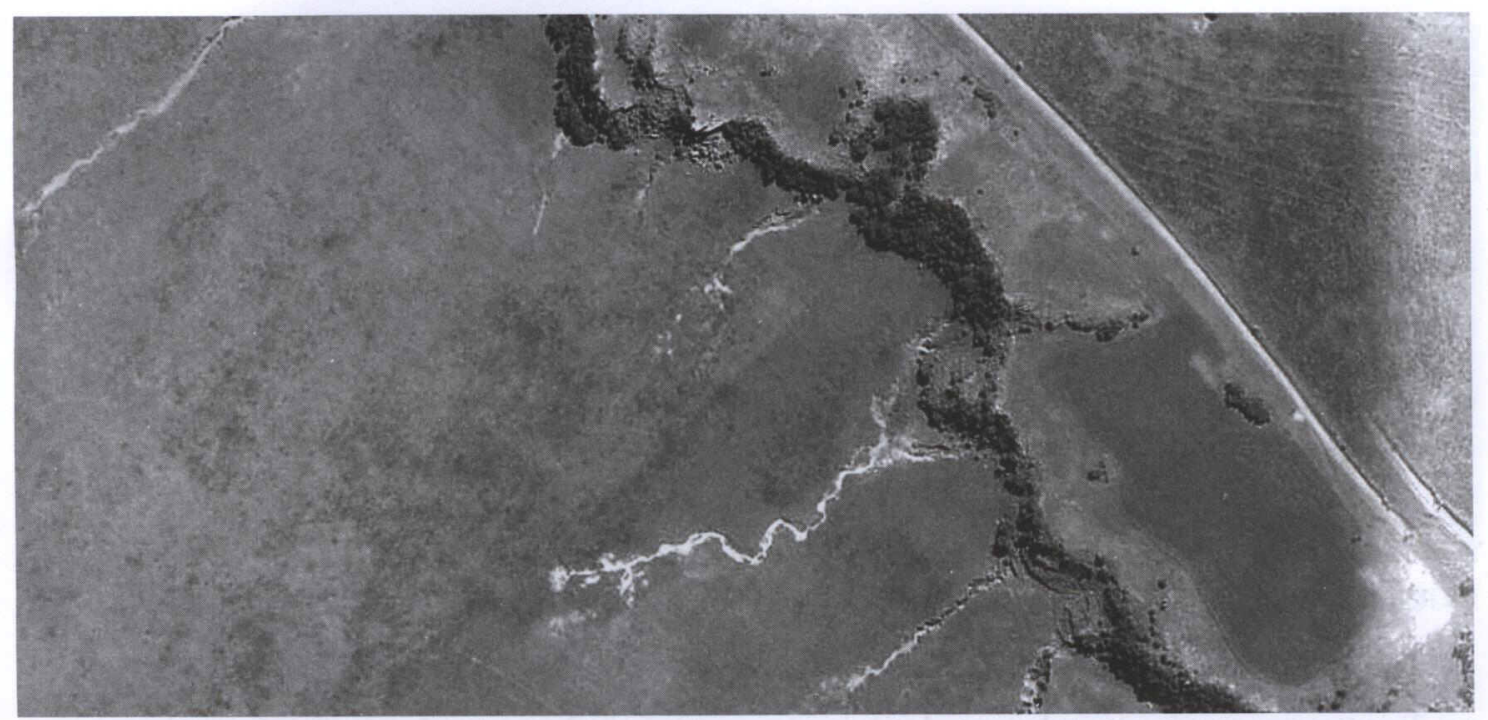

FIGURA 6 - Imagem de cornija arenítica, com processo erosivo (ravinas) atuante. (Google Earth, 2008).

\section{Cornijas de Arenito}

São degraus rochosos de tamanhos e formas variadas, salientes a meia encosta de algumas colinas de arenito. Interpretadas como estágio inicial na formação dos morrotes de arenito, as cornijas resultam do afloramento em blocos de porções de arenito fluvial ou eólico altamente coesos, devido, principalmente, à presença de um revestimento de óxido de ferro e/ou pela intensa cimentação dos grânulos, a partir da concentração de sílica.

Em muitas destas unidades, os processos erosivos, mais atuantes, geram ravinas e voçorocas, conferindo à paisagem um aspecto de degradação ambiental, característico de áreas em processo de arenização (Figura 6).

\section{Morrotes}

Conhecidos regionalmente como "cerros", os morrotes, sob o ponto de vista geomorfológico, constituem elevações de terreno superiores às colinas, tendo encostas relativamente íngremes. $\mathrm{Na}$ área em estudo, a unidade se diferencia em morrotes de arenito e morrotes vulcânicos, com base nas características do substrato rochoso.

\section{Morrotes de arenito}

São unidades formadas a partir da resistência da rocha frente aos processos de intemperismo. Isto ocorre devido à alta coesão de grânulos, resultante da cimentação de porções do arenito, a partir da concentração de óxido de ferro ou sílica, que confere maior resistência à rocha frente à ação erosiva. Sempre dispostos na parte superior de colinas areníticas, estas unidades possuem amplitudes médias de 20 a 30 metros e vertentes com elevadas declividades, formando escarpas rochosas com topo frequentemente reto e aplainado (Figura 7).

$\mathrm{Na}$ maioria das vezes, o topo, aplainado e predominantemente rochoso, apresenta inúmeras fendas. Em certos casos, apresenta-se uma camada de solo mais desenvolvida e uniforme, sempre conservando, todavia, o caráter arenoso. A encosta concentra um acúmulo de blocos e detritos rochosos de tamanhos variados, originados a partir do desprendimento da rocha formadora da escarpa. Na base destes morrotes são também identificados, com muita frequência, processos geomorfológicos relacionados à erosão, na área de contato com a coli- 


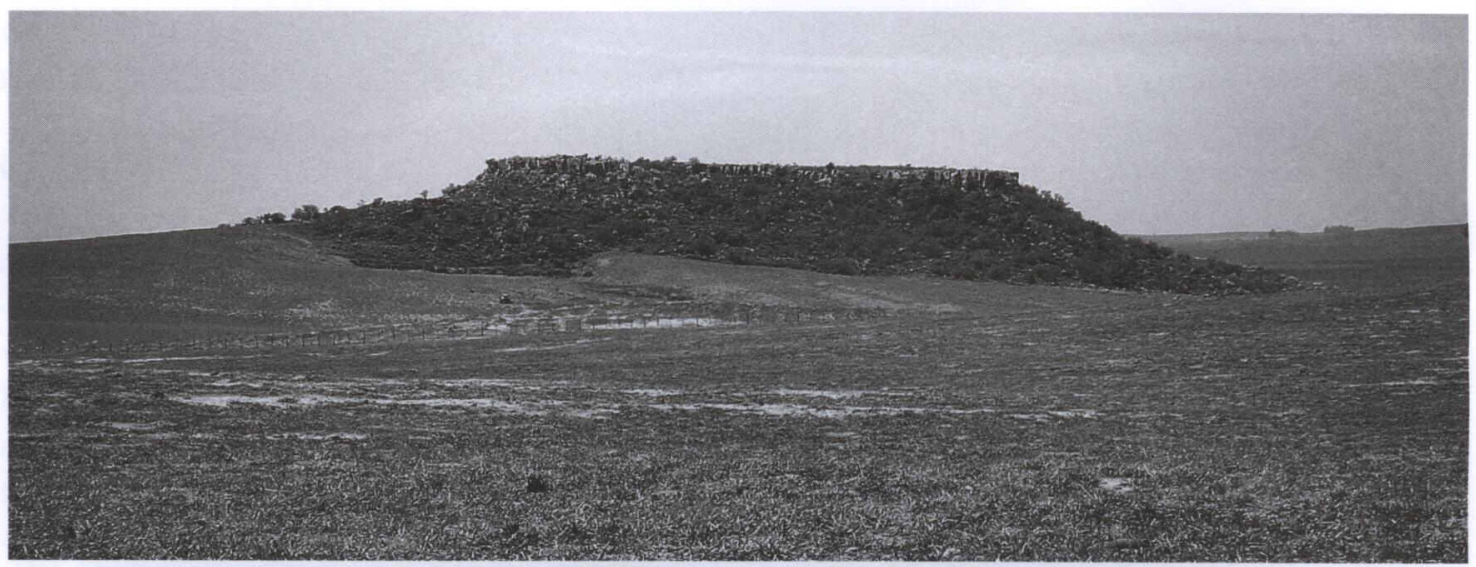

FIGURA 7 - Vista da encosta ocidental do Cerro da Cascavel, um típico morrote de arenito fluvial (2008).

na. Tais processos, uma vez desencadeados, resultam na formação de ravinas, voçorocas e, até mesmo, de areais consideráveis.

Apesar da área pouco expressiva na bacia em estudo, os morrotes de arenito merecem atenção especial, pois apresentam características muito particulares no tocante ao substrato rochoso, ao relevo e, principalmente, à vegetação. Cabe salientar-se, ainda, que grande parte dos morrotes de arenito foi pouco alterada pela ação antrópica.

\section{Morrotes vulcânicos}

Unidades de menor expressão na área em estudo, os morrotes vulcânicos recebem esta designação por apresentarem substrato de rochas vulcânicas básicas. Chamados, regional- mente, de "cerros redondos", tais morrotes apresentam elevações superiores às colinas vulcânicas, com amplitudes em torno de 20 metros, encostas íngremes e topos nitidamente arredondados (Figura 8). Os solos neles desenvolvidos, do tipo Neossolo Litólico e Cambissolos, apresentam horizontes muito reduzidos ou inexistentes, além de pequenos afloramentos de rocha, na forma de lajes fraturadas e/ou blocos arredondados de tamanhos reduzidos.

\section{Planície de Acumulação}

Tratam-se de áreas planas que acompanham o curso principal da bacia hidrográfica e alguns afluentes de maior porte (Figura 9). A unidade atinge proporções consideráveis no médio e baixo curso, a partir da cota de 120 metros. For-

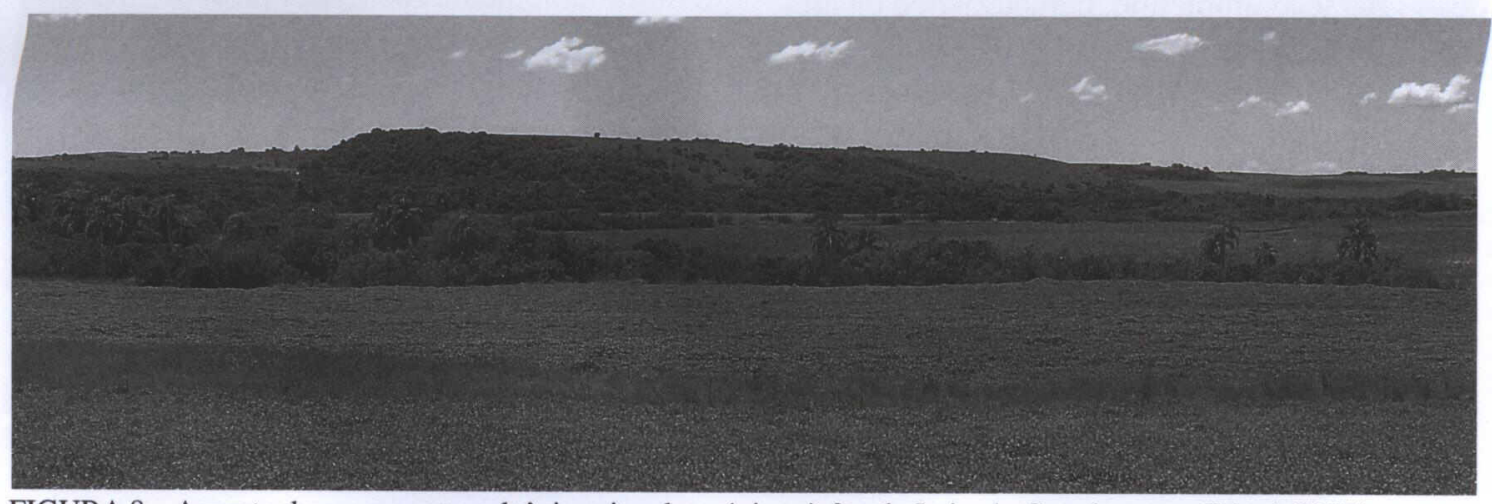

FIGURA 8 - Aspecto de um morrote vulcânico situado próximo à foz do Lajeado Grande com o Ibicuí (2007). 


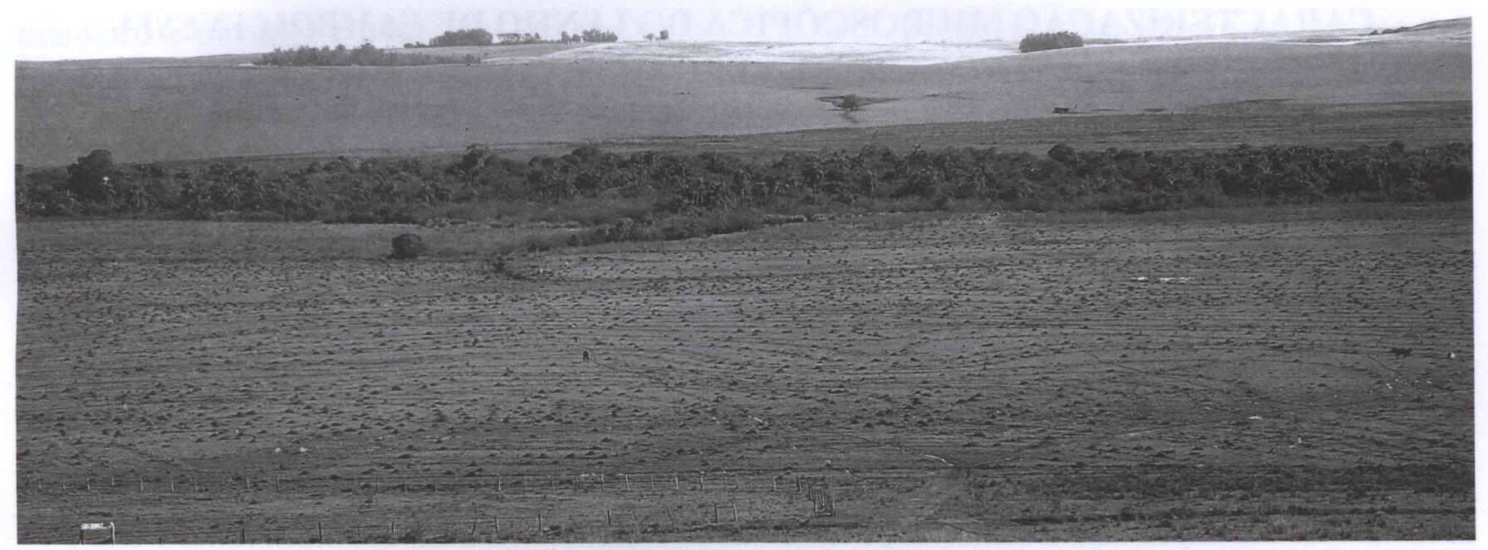

FIGURA 9 - Vista parcial da planície de acumulação, no baixo curso do Lajeado Grande (2008).

mada a partir da deposição alúvio-colúvio, concentra tanto material erodido das regiões de interflúvio, transportados pela ação das águas superficiais, como sedimentos aluviais depositados em períodos de transbordamento dos canais de drenagem. Grande parte desta planície constitui várzeas de solos férteis e hidromórficos, principalmente de Planossolos e/ou Gleissolos, com baixa capacidade de infiltração e drenagem.

\section{CONSIDERAÇÕES FINAIS}

O estudo do ambiente físico na bacia hidrográfica do arroio Lajeado Grande permite o reconhecimento de seis unidades morfolitológicas, definidas com base em aspectos geológicos e geomorfológicos do terreno. A caracterização do espaço físico em unidades homogêneas produz uma base de dados fundamental para entender-se a distribuição da vegetação natural, bem como os processos que atuam na dinâmica da paisagem.

Por fim, espera-se que este estudo venha a contribuir com o avanço do conhecimento fitogeográfico do oeste sul-rio-grandense, ser- vindo de subsídio a futuros trabalhos, bem como a propostas de manejo e gestão ambiental.

\section{REFERÊNCIAS BIBLIOGRÁFICAS}

BOTELHO, M. H. Águas de Chuva: engenharia das águas pluviais nas cidades. São Paulo: Edgard Blücher, 1998. 237 p.

IPT. Mapeamento Geomorfológico do Estado de São Paulo. São Paulo, 1981. 130 p. Escala 1:500.000. v. 2. (IPT, $\mathrm{n}^{\circ} 1183$ ).

LOLLO, J. A. de. O uso da técnica de avaliação do terreno no processo de elaboração do mapeamento geotécnico: sistematização e aplicação na quadrícula de Campinas. 1996. 250 f. Tese (Doutorado - EESC/USP), Universidade de São Paulo, São Carlos, 1996.

PAULA, P. M.; ROBAINA, L. E. S. Zoneamento Ambiental na Bacia do Lajeado Grande - RS. Caderno de Resumos. IX Simpósio Brasileiro de Geografia Física Aplicada, Unisinos, 2001. p. 473-473.

STRAHLER, A. Geografia Física. Barcelona: Omega, 1974. 236 p.

TRENTIN, R.; ROBAINA, L. E. S. Metodologia para mapeamento geoambiental no oeste do Rio Grande do Sul. Anais. XI Simpósio Brasileiro de Geografia Física Aplicada. São Paulo: USP, 2005. p. 173-182. 